\title{
Tailoring seasonal climate forecasts for hydropower operations
}

\author{
P. Block \\ International Research Institute for Climate and Society, Columbia University, Palisades, New York, USA \\ Received: 1 June 2010 - Published in Hydrol. Earth Syst. Sci. Discuss.: 24 June 2010 \\ Revised: 19 March 2011 - Accepted: 31 March 2011 - Published: 29 April 2011
}

\begin{abstract}
Integration of seasonal precipitation forecasts into water resources operations and planning is practically nonexistent, even in regions of scarcity. This is often attributable to water manager's tendency to act in a risk averse manner, preferring to avoid consequences of poor forecasts, at the expense of unrealized benefits. Convincing demonstrations of forecast value are therefore desirable to support assimilation into practice. A dynamically linked system, including forecast, rainfall-runoff, and hydropower models, is applied to the upper Blue Nile basin in Ethiopia to compare benefits and reliability generated by actual forecasts against a climatology-based approach, commonly practiced in most water resources systems. Processing one hundred decadal sequences demonstrates superior forecast-based benefits in 68 cases, a respectable advancement, however benefits in a few forecast-based sequences are noticeably low, likely to dissuade manager's adoption. A hydropower sensitivity test reveals a propensity toward poor-decision making when forecasts over-predict wet conditions. Tailoring the precipitation forecast to highlight critical dry forecasts minimizes this inclination, resulting in $97 \%$ of the sequences favoring the forecast-based approach. Considering managerial risk preferences for the system, even risk-averse actions, if coupled with forecasts, exhibit superior benefits and reliability compared with risk-taking tendencies conditioned on climatology.
\end{abstract}

\section{Introduction}

Seasonal climate forecasting capabilities continue to advance, attributable predominantly to enhanced observations, computing power, better physical understanding of the climate system, and experience (Barnston et al., 1994, 2005;

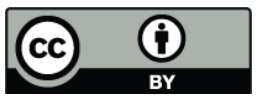

Correspondence to: P. Block (pblock@iri.columbia.edu)
Goddard et al., 2003). Their principle goal is to reduce climate-related risks, providing advance information to potentially improve decision-making and increase societal benefits, especially over the long term. Currently, however, there exists little evidence of direct forecast use in operations, especially in water resources management, even in regions of scarcity. This is often ascribed to water managers tendency to act in a risk averse manner, "poor" forecast skill or scale, difficulty in integrating forecasts into existing decision support systems, lack of focus on specific user needs, anticipated shifts in the water sector, management and political disincentives, individual and institutional inflexibility, behavioral effects, and informational constraints (Pulwarty and Redmond, 1997; Hamlet et al., 2002; Ritchie et al., 2004; Rayner et al., 2005; Broad et al., 2007; Johnston et al., 2007; Lemos, 2008; Millner, 2009; Ziervogel et al., 2010).

The abundance of research and literature over the past decade identifying challenges and impediments should act as a stimulus for case studies evaluating potential economic benefits and improved reliability through forecast inclusion. These two determinants are powerful motivators for water resources managers and policy makers, and forecastinduced positive outcomes may provide incentive to address other barriers. Previous research studies have advocated for demonstrations of such effective forecast use (e.g. Pagano et al., 2001). Minimal applications within the water resources community, however, seek to quantify the actual monetary and reliability gains or losses of including a forecast in comparison to commonly accepted climatology-based operations (i.e. based on average climate conditions), and most of those examples refer only to perfect forecasts, excepting a few (e.g. Yeh et al., 1982; Kim and Palmer, 1997; Yao and Georgakakos, 2001; Hamlet et al., 2002; Chiew et al., 2003; Maurer and Lettenmaier, 2004; Axel and Céron, 2007; Sankarasubramanian et al., 2009). An absence in forecast adoption is unmistakable (Rayner et al., 2005), and further exaggerated in developing countries with limited hydrologic observations (Patt et al., 2007; Ziervogel et al., 2010).

Published by Copernicus Publications on behalf of the European Geosciences Union. 
This motivates the current research to demonstrate the improved economic value and reliability resulting from a flexible seasonal climate forecast - hydropower modeling system, given biophysical, policy, and economic constraints, by mitigating losses and capitalizing on opportune conditions (Hellmuth et al., 2007). Forecasts, coupled with flexible operating rules, may lead to optimal or more efficient reservoir management of storage and release volumes based on expected probabilistic future conditions (Karamouz and Vasiliadis, 1992; Faber and Stedinger, 2001). Gaining an understanding of expectations from a realistic, imperfect forecast imbedded in a dynamic operational system could prove enticing for water managers to adopt forecast inclusion, or justification for rejecting. Appreciating benefits and reliability in a context of climate variability begins to address a number of the aforementioned impediments (summarized well in Ziervogel et al., 2010).

This paper commences with a description of the application site, the Blue Nile basin in Ethiopia's highlands, followed by an outline of the linked forecast-hydropower modeling system. The economic value and reliability produced from the seasonal climate forecast driven system are then compared with a non-forecast approach, ending with a discussion and conclusion.

\section{Description of application site}

Ethiopia possess abundant water resources and hydropower potential, second only to the Democratic Republic of Congo in all of Africa, yet only two percent of this potential has been developed (World Energy Council, 2007). Currently, $83 \%$ of Ethiopia's population lacks access to electricity, with $94 \%$ still relying on fuel wood for daily cooking and heating (Tegenu, 2006). The Ethiopian government is therefore pursuing ambitious plans and programs to develop hydropower in an effort to substantially reduce poverty and create an atmosphere for social change. It has been shown that access to electricity, including rural electrification, is a key to poverty reduction in Ethiopia (MoFED, 2006). Implementation, however, is not trivial, especially due to the large financing and investment challenges, as well as required institutional capacity.

The Blue Nile headwaters emanate at the outlet of Lake Tana in the Ethiopian highlands, and are joined by many important tributaries, draining $180000 \mathrm{~km}^{2}$ in the central and southwestern Ethiopian highlands (Steenhuis et al., 2009) becoming a mighty river long before it reaches the lowlands and crosses into Sudan (Fig. 1). It stretches nearly $850 \mathrm{~km}$ between Lake Tana and the Sudan-Ethiopia border, with a fall of $1300 \mathrm{~m}$; the grades are steeper in the plateau region, and flatter along the low lands. Very few stream gauges exist along the Blue Nile River within Ethiopia, and those that do tend to have spotty or limited records, and are often not publicly available. Roseires dam in Sudan presents the first

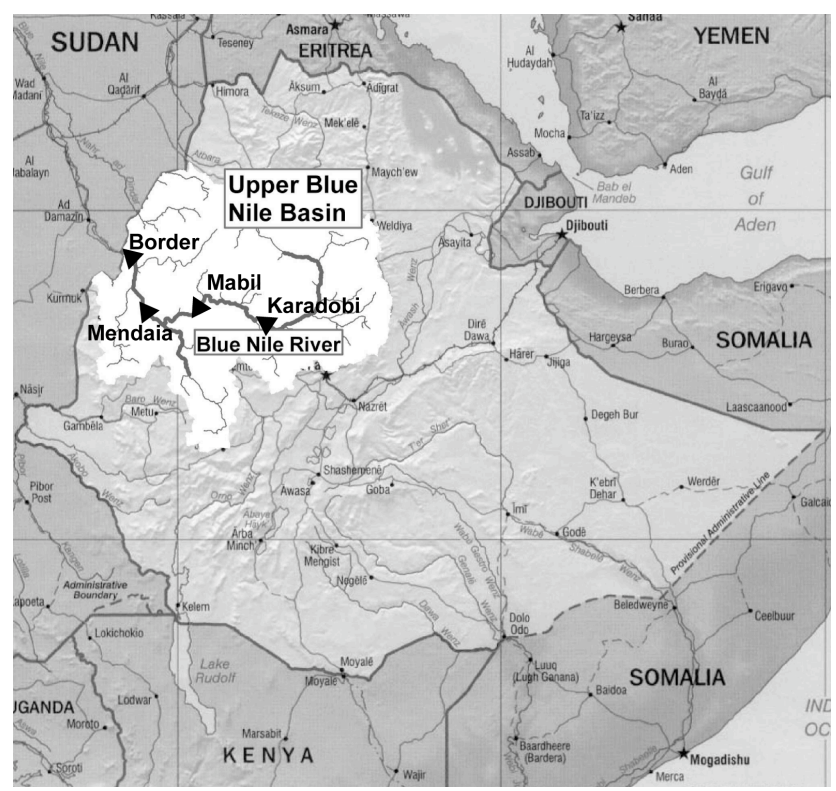

Fig. 1. The upper Blue Nile basin, Ethiopia, including proposed large-scale hydropower dams. Base map courtesy of the PerryCastañeda Library map collection, University of Texas.

streamflow record of sufficient length; monthly averages are illustrated in Fig. 2.

The climate in the Blue Nile River basin varies between its inception in the wet, moderate highlands of Ethiopia and its confluence with the White Nile River in a drier, warmer region. Monthly precipitation records indicate a summer monsoon season, with highest totals in the June-September months (Block and Rajagopalan, 2007); seasonal precipitation averages in excess of $1000 \mathrm{~mm}$ in the highlands but only $500 \mathrm{~mm}$ near the Sudan border (Shahin, 1985; Sutcliffe and Parks, 1999), with significant interannual variability throughout as illustrated in Fig. 3a (solid line). Near the border, rains during this season account for nearly $90 \%$ of total annual precipitation, while in the highlands, approximately $75 \%$ of the annual precipitation falls during the monsoon season. The El Niño - Southern Oscillation (ENSO) phenomenon is a main driver of the interannual variability in seasonal precipitation in the basin, with El Niño (La Niña) events generally producing drier (wetter) than normal conditions (Block and Rajagopalan, 2007). Evaporation in the basin varies inversely with precipitation, favoring lesser annual rates in the highlands $(\sim 1150 \mathrm{~mm})$ compared with excessive rates $(\sim 2500 \mathrm{~mm})$ near the Sudan-Ethiopia border (Shahin, 1985; Sutcliffe and Parks, 1999).

In 1964, the United States Bureau of Reclamation (USBR), upon invitation from the Ethiopian government, performed a thorough investigation and study of the hydrology of the upper Blue Nile basin. Included in the USBR's study was an optimistic list of potential projects within Ethiopia, including preliminary designs of dams for 


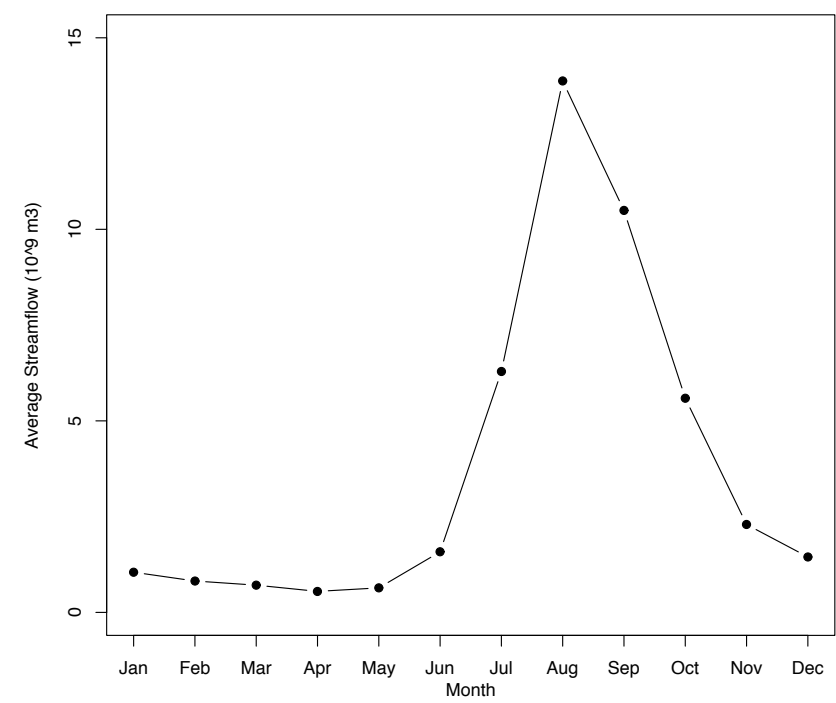

Fig. 2. Mean monthly streamflow at Roseires, Sudan, 1961-1990. Same as Fig. 1 in Block and Strzepek (2010).

irrigation and hydroelectric power along the main Blue Nile stem. The four major hydroelectric dams along the Blue Nile, as proposed by the USBR, are presented in Fig. 1. Operating in series, these four dams could impound a total of 73 billion cubic meters, which is equivalent to approximately 1.5 times the average annual runoff in the basin. The total installed capacity at design head would be 5570 megawatts (MW) of power, about 2.5 times the potential of the Aswan High Dam in Egypt, and capable of providing electricity to millions of homes. This would be an impressive upgrade over the existing $529 \mathrm{MW}$ of hydroelectric power within Ethiopia as of 2001 (Thomson Gale, 2006). Initial construction costs range from $\$ 1.8-\$ 2.2$ billion per dam; annual costs (operation and maintenance, scheduled replacement, and insurance) begin in the first year post-construction and range from \$12.5-\$17.9 million (Bureau of Reclamation, 1964). While none of these dams have actually been constructed, chiefly due to financial constraints, the Ethiopian Government still has intentions for their full development. For demonstration purposes, however, the dams are assumed online and functional, which is analogous to an operationallevel planning study, ideally providing insight into additional expected benefits with forecast inclusion.

\section{Linked modeling system}

To evaluate the expected benefits of forecast inclusion, in comparison to climatology-based operations, a linked modeling system approach is adopted. This allows processing and transformation of the Kiremt (June-September) monthly precipitation into streamflow for hydropower optimization along the Blue Nile River. The framework is structured by linking previously developed, independent models.
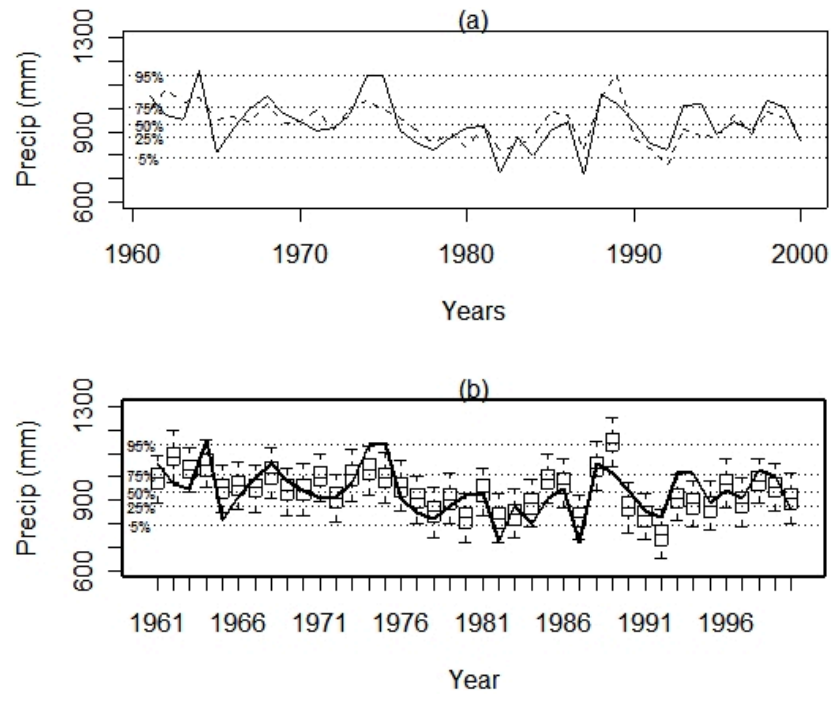

Fig. 3. Local polynomial June-September precipitation forecast modeling approach results. (a) Observed and cross-validated estimates with horizontal lines at percentiles from the observed seasonal precipitation. (b) Box plots of cross-validated ensembles with horizontal lines at percentiles from the observed seasonal precipitation. Observed data shown as solid line; cross-validated model estimates shown as dashed line in (a) and boxes in (b). Same as Fig. 11 in Block and Rajagopalan (2007).

\subsection{Structure and components}

Three major modeling components are required: precipitation forecast, rainfall-runoff, and hydropower/water systems optimization (Fig. 4). The forecast model (Block and Rajagopalan, 2007) predicts total seasonal (June-September) precipitation over the Blue Nile basin. One-season lead (March-May) predictors include sea level pressures, sea surface temperatures, geopotential height, air temperature, and the Palmer Drought Severity Index (PDSI), identified through correlation mapping with seasonal precipitation (e.g. Singhrattna et al., 2005; Grantz et al., 2005). The correlation patterns in sea surface temperatures and sea level pressures resemble ENSO features, yet are more skillful than common ENSO indices (Block and Rajagopalan, 2007). The remaining three predictors capture regional characteristics, with PDSI acting as a soil moisture surrogate.

A nonparametric forecast model based on local polynomial regression (Loader, 1999) is adopted to address various shortcomings common with linear regression, including artificially high skill scores stemming from limited data length and multicollinearity among predictors, regression coefficients being greatly influenced by a small number of outliers, often leading to a poor fit, and the inability to capture nonlinear relationships. In the nonparametric approach, estimation of the model function is performed "locally" at the point to be estimated; therefore no global mathematical relationship between predictors and seasonal precipitation 


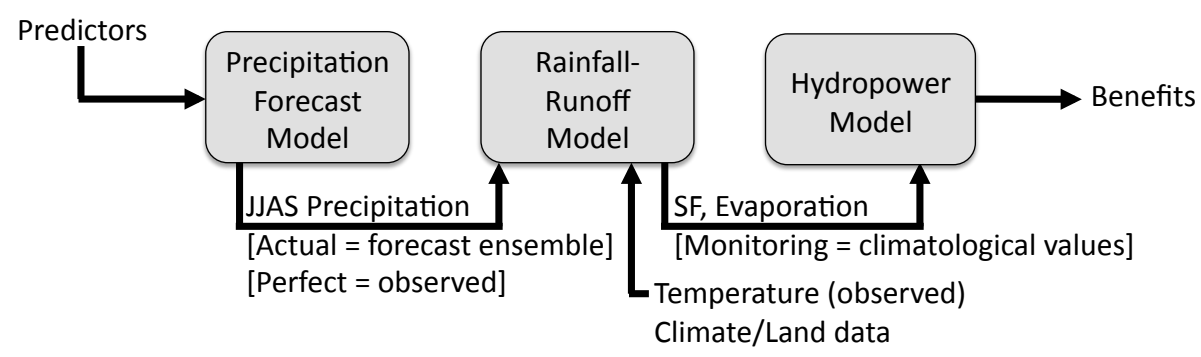

Fig. 4. The linked modeling system with a monthly time-step. JJAS = June-September, SF = streamflow.

exists. This "local" estimation provides the ability to capture features (i.e. nonlinearities) that might be present locally, without granting outliers any undue influence in the overall fit. Optimal model parameters and predictors (the five previously mentioned) are selected via the generalized cross validation score function (Craven and Wahba, 1979). A detailed implementation algorithm is available in Block and Rajagopalan (2007).

Unique forecast distributions for each year are created by adding normal random deviates (mean zero and standard deviation of the global predictive error) to the forecasted precipitation value (Helsel and Hirsch, 1995). These normal distributions represent the inherent uncertainty of the forecast prediction coming from the statistical model. Figure 3 illustrates the observed and modeled time-series for 1961-2000; forecast distributions are represented as box plots in Fig. 3b. Median values from the forecast distributions demonstrate a correlation coefficient of 0.69 with observations; a rank probability skill score of 0.39 , using the full distribution, is a marked improvement over climatology alone. Seasonal precipitation forecasts are disaggregated into monthly forecasts through a proportion vector calibrated on observed data.

The rainfall-runoff model employed is a derivative of the Watbal model (Yates, 1996; Yates and Strzepek, 1998), specifically calibrated to the Blue Nile basin. It is a semidistributed, average-monthly model, with lumped soil and vegetation type and distributed climatic inputs, applied to gridded data $\left(0.5^{\circ} \times 0.5^{\circ}\right.$ for this study). The model simulates changes in soil moisture and runoff, and is essentially an accounting scheme based on a conceptualized, onedimensional bucket that lumps both the root and upper soil layer. The model comprises two elements: the first is a water balance component that describes water movement into and out of a conceptualized basin; the second is the calculation of potential evapotranspiration, which is computed using the FAO Penman-Monteith approach (FAO, 1998). The water balance component of the model comprises three parameters: surface runoff, sub-surface runoff, and maximum catchment water-holding capacity. The simplified representation of soil moisture dynamics has been shown to adequately represent runoff changes due to climate fluctuations (Yates, 1996; Yates and Strzepek, 1998). A final module translates runoff into Blue Nile River streamflow for critical points throughout the basin by aggregating runoff from upstream grid cells, as determined with digital elevation maps.

Given the minimal availability of relevant hydrology data within the basin, rainfall-runoff model calibration and validation is contingent on a long streamflow record at the Roseires dam, just over the border in Sudan. Inflow into potential reservoirs is inferred; no validation at these points is possible. Clearly, additional data collection and sampling for improved rainfall-runoff modeling would be necessary prior to final design of the dams and reservoirs.

The hydropower/reservoir model selected is IMPEND, the Investment Model for Planning Ethiopian Nile Development (Block and Strzepek, 2010). It is classified as a planning tool with operational-level detail to help define feasibility and expectations of project choice. IMPEND is a deterministic water resources system model requiring a single input file of monthly streamflow and net evaporation at the four proposed Ethiopian dam locations and at the existing Roseires dam in southeastern Sudan (all in series). The model thus encompasses the Blue Nile River from its inception at Lake Tana to the Roseires dam, just beyond the Sudan-Ethiopian border. The current version values hydropower at 8 -cents per kilowatt-hour; reservoir head represents the decision variable and net present benefits constitutes the objective value.

When linked with the forecast and rainfall-runoff models, IMPEND is analogous to an implicit stochastic optimization process, with two notable exceptions (Loucks et al., 1981; Draper, 2001). First, model foresight is limited to 12 months (not the full time-sequence of analysis), and second, that foresight is imperfect when based on forecasts or climatology (see Sect. 3.3). The model maximizes hydropower benefits given the hydrologic state variables, including the existing reservoir storage volume and limited foresight inflow forecast. Specific model equations and details are provided in Block and Strzepek (2010).

A key attribute of the model is its ability to accept monthly input data varying from year to year, which is critical for proper performance assessment. Analysis based solely on a climatological perspective may well misjudge long-term project benefits (Block et al., 2008). IMPEND is also capable of assessment over various interest (or discount) rates; for the purposes of this study, this rate has been restricted to $10 \%$. This social rate of discounting has been used by others 
(e.g. Jabbar et al., 2000) and falls within the range of discount rates experienced by Ethiopia within the last five years (Central Intelligence Agency, 2006). A final noteworthy characteristic is the flexibility of downstream flow policies, modulated by the downstream flow constraint established at the entrance to Roseires dam. The policy employed here allows for up to five percent of the annual flow passing the border to be impounded within Ethiopia.

IMPEND may be configured to account for transient (filling) conditions for dams coming online, however for this analysis, all reservoirs are assumed initially filled to design height to mimic operational aspects. Reservoir operations are not restricted to explicitly following established rule curves, but rather are flexible, optimizing operations based on expected future streamflow. Operations are, however, constrained to meet or exceed a future target storage level, as described in Sect. 3.3. Benefits attributable to climate forecasts in hydropower optimization are an aspect not often considered. For a climatology-based operation, however, for which future streamflows are simply based on observed monthly means, this approach essentially collapses to a process analogous to following a rule curve.

\subsection{Data}

For the forecast model, global atmospheric and oceanic variables, including sea surface temperature, sea level pressure, geopotential height, and air temperature, were obtained from the National Oceanic and Atmospheric Administration's (NOAA's) Climate Diagnostics Center (CDC), based on National Centers for Environmental Prediction-National Center for Atmospheric Research (NCEP-NCAR) reanalysis data (Kalnay et al., 1996). These are monthly average values on a $2.5^{\circ} \times 2.5^{\circ}$ grid for 1949 to the present. PDSI values (Dai et al., 2004), also at monthly time scales and on a $2.5^{\circ} \times 2.5^{\circ}$ grid, for $1870-2003$, were provided by NCAR's Climate and Global Dynamics Division. Observed precipitation data (the predictand) are part of the Climatic Research Unit (CRU) time series 2.0 dataset, on a $0.5^{\circ} \times 0.5^{\circ}$ grid resolution, obtained from the University of East Anglia, Norwich, United Kingdom (Mitchell and Jones, 2005).

In addition to the June-September monthly precipitation produced by the forecast model, the rainfall-runoff model requires inputs of mean daily temperature and the diurnal temperature range, acquired from the CRU dataset (Mitchell and Jones, 2005). Precipitation for months other than JuneSeptember represents climatology based on the same dataset. Monthly streamflow and net evaporation outputs are produced monthly.

Physical, hydrologic, and climatic data required for building and running IMPEND were acquired from a number of sources. Dam, reservoir, and power characteristics are provided in the USBR preliminary study (Bureau of Reclamation, 1964). Observed streamflow records for calibration and validation in the upper Blue Nile basin are publicly available through numerous sources, including NCAR's ds552.1 dataset (Bodo, 2001). The rainfall-runoff model provides streamflow and net evaporation. IMPEND outputs include project benefits or net benefits (discounted back to the simulation start year), energy production, and reservoir levels at monthly intervals.

\subsection{Forecasting approaches}

To quantify the value of a seasonal precipitation forecast carried through the linked system, three types of forecasts are evaluated through a hindcast: perfect, actual (imperfect), and monitoring (based on climatology). Decision-making is contingent on current conditions (e.g. reservoir storage) and an outlook of precipitation over the ensuing 12 months. In the perfect forecast case, the 12-month foresight period consists of observed precipitation, and represents an upper bound on expected benefits possible through forecast improvement. The actual and monitoring forecast approaches do not use perfect precipitation foresight, but rather a combination of imperfect forecasts and climatology out 12 months, as detailed below. The selection of 12 months, as opposed to a shorter foresight, is based on the large reservoir storage capacity, and also facilitates constraining reservoir levels to prevent dumping for short-term gains in the optimization.

For the perfect forecast case, observed precipitation and temperature are fed into the rainfall-runoff model to generate a streamflow and net evaporation sequence to drive the hydropower model. Given the lack of observational data at the inlet of the reservoirs, the streamflow and net evaporation produced by the rainfall-runoff model based on observed precipitation are substituted for observations. Operational decisions in the hydropower model are optimized in the current step reflective of the existing reservoir storage and inflows over the next 12 months, subject to constraints, including the target storage level. Marching forward one month, the hydropower model receives new information regarding the time-step 12 months out, and reoptimizes reservoir decisions accordingly to maximize benefits. This iterative approach forms a set of sequential deterministic problems (e.g. Stedinger et al., 1984; Marino and Loaiciga, 1985a,b).

The actual forecast approach follows a similar overall progression, excepting application of forecasted precipitation for June-September, with climatological precipitation in other months, as inputs into the rainfall-runoff model. Observed temperatures are also applied. In any given month, the hydropower model optimizes based on existing reservoir storage and inflows over the next 12 months, as in the perfect forecast case, however prior to May, when the forecast is issued, streamflow and net evaporation values are based only on climatological precipitation and persistence. Thus in May of every year, streamflow and net evaporation for each of the subsequent 12 months of the sequence are updated, reflecting the new precipitation forecast. 
Decision-making for the monitoring approach is simply based on optimizing over current reservoir conditions and climatological streamflow and net evaporation, the common approach for most water managers.

Thus, for the actual and monitoring approaches, an optimal release is selected in the current month time-step, conditioned on future imperfect forecast or climatological inflows, respectively, and start-of-month reservoir storage. Reservoir storage after releases is subsequently computed via a mass balance using the forecast or climatological inflow. The endof-month reservoir storage, however, must be updated (or corrected) by the difference between the imperfect or climatological inflow and the observed inflow; reservoir storage is increased or decreased accordingly. This is suboptimal, from the hydropower model perspective, but realistic given inflow forecast errors. Finally, the end-of-month reservoir storage becomes the existing storage for the ensuing month, and the iterative optimization scheme is updated (Marino and Loaiciga, 1985a,b). Observed inflows are produced by the rainfall-runoff model utilizing observed precipitation and temperature, as discussed previously.

\subsection{Hydroclimatic sequences development and evaluation}

To force the linked modeling system, decadal sequences of monthly hydroclimatic input variables (precipitation forecast, temperature) need to be assembled. It is commonly accepted that forecast distributions better capture observations in some years (or seasons) than others, thus the choice of decades allows for examination of compounding effects and tends to smooth out noisy monthly optimization behavior. The goal here is to compare adoption of approaches over time, not for any isolated event. To start, four decadal sequences are constructed from the model hindcast period (1961-1970, 1971-1980, 1981-1990, 1991-2000), providing a comparison over varying climatic conditions. The perfect approach applies observed precipitation, the actual approach applies means of the imperfect precipitation forecast distribution, and the monitoring approach applies climatological precipitation. To capture forecast uncertainty in the actual approach and translate it into benefits, 100 additional sequences are assembled for each of the four decades by randomly drawing from the forecast distribution of the appropriate year (Datta and Houck, 1984; Datta and Burges, 1984). Each of the 100 sequences is then processed through the system of models, including optimizing operations contingent on inflows, existing reservoir storage, and a target storage level.

The number of sequences may be further augmented by bootstrapping from the observed record and in the case of the actual approach, drawing from the forecast distributions. The goal of these additional sequences is to better understand the plausible effects of potential climatic variability (e.g. juxtaposition of wet or dry periods not experienced in the observed record) and model uncertainty (including forecast and hydrology). This is analogous to a sensitivity-type approach to appreciate potential effects on system benefits.

One-hundred bootstrapped sequences are formed for all three approaches simultaneously and processed through the linked model system according to the following algorithm (see Fig. 4 for flow chart):

1. Randomly select a year, 1961-2000.

2a. Perfect: Retain monthly precipitation observations.

2b. Actual: Draw from the precipitation forecast distribution from the year selected (Fig. 3) and disaggregate to June-September months. For each non June-September month, fill the precipitation record with monthly climatological values.

3. Repeat steps (1)-(2) ten times (with year replacement) to form a decade-long record.

4. Perfect and Actual: Process the sequence through the rainfall-runoff model to produce monthly net evaporation and streamflow into the reservoir.

5a. Perfect and Actual: process the net evaporation and streamflow sequences through the IMPEND hydropower model to generate hydropower benefits. Actual approach requires reservoir storage update based on observed inflows.

5b. Monitoring: process decade-long climatological net evaporation and streamflow sequences through IMPEND to generate hydropower benefits. Requires reservoir storage update based on observed inflows.

6. Repeat steps (1)-(5) one hundred times.

An evaluation of the temporal persistence of interannual June-September total seasonal precipitation reveals no particular persistence at any lag, therefore interannual streamflow may be considered a random process, justifying a bootstrap approach to construct decadal sequences. Monthly persistence between years, specifically December to January, exists weakly, but has not been preserved for the perfect approach; this is the dry season, and variability (let alone quantity) is small, producing negligible differences. For the actual and monitoring approaches, climatological values are assumed for December and January, so persistence is irrelevant.

The three forecasting approaches are evaluated by comparing the sum of monthly hydropower benefits, aggregated to decadal totals. Initial comparisons include approaches with all four proposed dams online; latter comparisons include only Karadobi, the farthest upstream dam site.

Two performance metrics, analogous to reliability and resilience, are created for further comparison between actual 
Table 1. Decadal reliability and annual resilience for two forecasting approaches in comparison to monitoring (climatology). Four-reservoir scheme only, with sequences based on observed decades in chronological order.

\begin{tabular}{|c|c|c|c|c|c|c|c|c|}
\hline \multirow{3}{*}{$\begin{array}{l}\text { Forecast Approach } \\
\text { (Four-reservoir scheme) }\end{array}$} & \multicolumn{8}{|c|}{ Decades } \\
\hline & \multicolumn{2}{|c|}{$1960 \mathrm{~s}$} & \multicolumn{2}{|c|}{$1970 \mathrm{~s}$} & \multicolumn{2}{|c|}{$1980 \mathrm{~s}$} & \multicolumn{2}{|c|}{$1990 \mathrm{~s}$} \\
\hline & Rel & Res & Rel & Res & Rel & Res & Rel & Res \\
\hline Full forecast & 0 & 0.33 & 0.29 & 0.37 & 0.97 & 0.52 & 0.84 & 0.51 \\
\hline $\mathrm{BN}$ tercile forecast only & 0.13 & 0.70 & 1.0 & 0.60 & 1.0 & 0.58 & 0.85 & 0.48 \\
\hline
\end{tabular}

Note: $\mathrm{BN}=$ below normal precipitation; Rel = decadal reliability, Res = annual resilience

forecast and monitoring benefits. Reliability is represented as:

If $\mathrm{FB}_{t}>\mathrm{MB}_{t} z_{t}=1$, else $z_{t}=0$

Reliability $=\left(\Sigma_{t} z\right) / n$

where $\mathrm{FB}_{t}$ represents hydropower benefits from the actual forecast model system at time-step $t, \mathrm{MB}$ are the monitoring approach system benefits, $z$ is a counting scalar, and $n$ equals the total number of time-steps. This comparative reliability may therefore vary from $0-1$; values less than 0.5 infer higher overall reliability by the monitoring methodology, while values greater than 0.5 indicate higher overall reliability by the actual forecast approach. Resilience measures the ability of the actual forecast system to respond to years with benefits lower than the monitoring approach with greater benefits in the following year.

If $\mathrm{FB}_{t}<\mathrm{MB}_{t}$ and if $\mathrm{FB}_{t+1}>\mathrm{MB}_{t+1}$ then $y_{t}=1$

If $\mathrm{FB}_{t}<\mathrm{MB}_{t}$ and if $\mathrm{FB}_{t+1}<\mathrm{MB}_{t+1}$ then $y_{t}=0$

Resilience $=\left(\Sigma_{t-1} y\right) / m$

where $y$ is a counting scalar, and $m$ equals the total number of occurrences. Resilience varies from 0-1 with larger values signifying greater actual forecast system resilience.

\section{Economic value and reliability of seasonal climate forecasts}

The benefits of the linked model system drawing on the three forecasting approaches, reliabilities between the actual forecasting and monitoring approaches, and application of a tailored actual forecast to address water manager's riskaversion are presented in the following section.

\subsection{Chronological analysis of observed record}

Using the four decades from the observed record, decadal hydropower benefits of the linked model system from the perfect, actual forecast, and monitoring approaches are assessed (Fig. 5). Box plots characterize the expected benefit

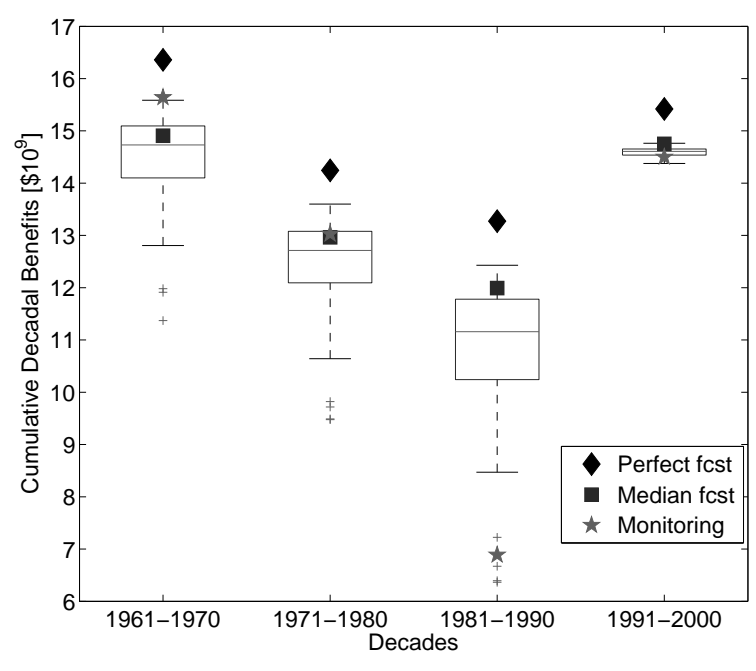

Fig. 5. Cumulative decadal hydropower benefits for four observed decades using the perfect (diamond), actual (median, square), and monitoring (climatology, star) precipitation forecasts. Box plots characterize the expected benefit distribution of the 100 sequences drawn from the forecast distributions.

distribution of the 100 sequences drawn from the forecast distributions. Dams are assumed to be online from the onset. Only the 4-reservoir scheme is displayed, as the singlereservoir (Karadobi only) scheme behaves quite similarly. As expected, the perfect forecast outperforms both the actual and monitoring forecasts; with the exception of the first decade, the actual forecast system benefits are on par or surpass those of the monitoring system. Poor forecasts in the early years, especially 1962-1963, for which notably wetter than observed conditions are predicted, contribute to the slightly inferior actual forecast system performance of that decade. The third decade, for which the actual forecast approach benefits far exceed those of the monitoring approach, is a relatively dry period with two exceptionally dry years (1982, 1987). The actual forecast model does predict drier than normal conditions for those years, but not to the extreme observed. In summary, while for three decades there is little appreciable difference between the median-based forecast and the no-forecast approaches, for the 1980s decade, the 
Table 2. Decadal and annual reliability and resilience for two forecasting approaches in comparison to monitoring (climatology). Single-reservoir scheme only based on bootstrapped sequences.

\begin{tabular}{lccc}
\hline Forecast Approach & \multicolumn{2}{c}{ Reliability } & Resilience \\
\cline { 2 - 3 } (single reservoir scheme) & Decadal & Annual & Annual \\
\hline Full forecast & 0.68 & 0.58 & 0.48 \\
BN tercile forecast only & 0.97 & 0.72 & 0.69 \\
\hline
\end{tabular}

Note: $\mathrm{BN}=$ below normal precipitation

difference is stark; it is these major hits that water managers wish to avoid. The range of actual forecast decadal benefits, representing forecast uncertainty, is not trivial, as illustrated by the box plots, especially for the first three decades. For the 1990s decade, observations are predominantly in the interquartile range, with limited extreme years, thus producing a very tight benefit distribution. Not surprisingly, benefits derived from the median forecasts are superior to the median of decadal sequences based on randomly drawing from the forecast distributions. Reliability and resilience of the actual approach based on the 100 sequences, as compared with the monitoring approach, are very low for the first two decades, and starkly higher for the last two (Table 1). From this preliminary analysis, it would appear there is value in using an actual seasonal forecast, compared with climatology, to potentially reduce variability in benefits and buffer against considerable losses, however the low reliability and resilience in the first decades is concerning.

\subsection{Sampling from the observed record}

A comparison of decadal benefits between the actual forecast and monitoring system approaches for the 100 bootstrapped sequences, under both the 4-reservoir and single-reservoir (Karadobi only) schemes, is illustrated in Fig. 6. Points above the 1-to-1 line represent sequences for which the actual forecast method's cumulative benefits surpass those of the monitoring method; similarly, points below the line favor the monitoring method. For both the multi and single reservoir schemes, the majority of points are bundled around the 1-to-1 line at the higher benefit end, not clearly favoring either forecasting approach. For sequences resulting in lower benefits, the actual forecast method tends to fare better. Negative benefits are possible due to a penalty function applied to low reservoir levels/low outlet flows, but contribute minimally. Reliability for the single reservoir scheme is 0.68 and 0.58 for decadal and annual (1000 years) sequences, respectively, indicating added value for actual forecast inclusion (Table 2). Resilience is 0.48 for the annual assessment, indicating an immediate rebound for approximately half the occurrences (Table 2). Lack of resilience may be explained by multiple sequential poor forecasts, or the
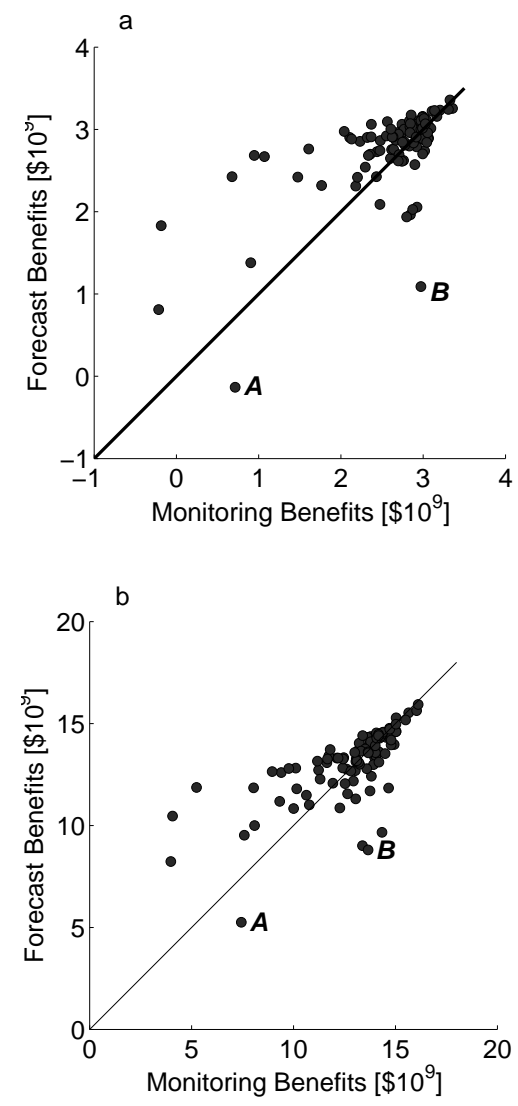

Fig. 6. Comparison of hydropower benefits between monitoring and actual forecast linked model approaches for (a) single-reservoir (Karadobi), and (b) 4-reservoir schemes.

inability of the system to respond timely to a poor forecast, even if the subsequent year's forecast is adequate. The multireservoir scheme reliability and resilience (not reported) is almost identical.

Although the overall results are generally positive, specific sequences, such as decades labeled $A$ and $B$ on Fig. 6, may be severe enough to dissuade managers from accepting an actual forecasting approach. Even though the likelihood of these events occurring is small, the risk may still be sufficient. Examining these specific sequences in detail is enlightening. Annual streamflow and benefits for decade $A$ from the actual and monitoring forecast approaches, for the single-reservoir scheme, are illustrated in Fig. 7. Most notably from the streamflow sequence is the over-prediction by the actual forecast system in years 2-3 and 5. The ramifications of this are evident in the annual benefits figure: in years following a poor forecast, benefits drop noticeably in comparison to the monitoring approach, especially when forecasting greater than observed "wet" conditions. (The figure illustrates discounted benefits, so a general downward trend is not unexpected.) This phenomenon is also apparent upon inspection of decade $B$, presented in Fig. 8, in which years 3 and 5-7 all represent forecasts greater than observed. Similar 

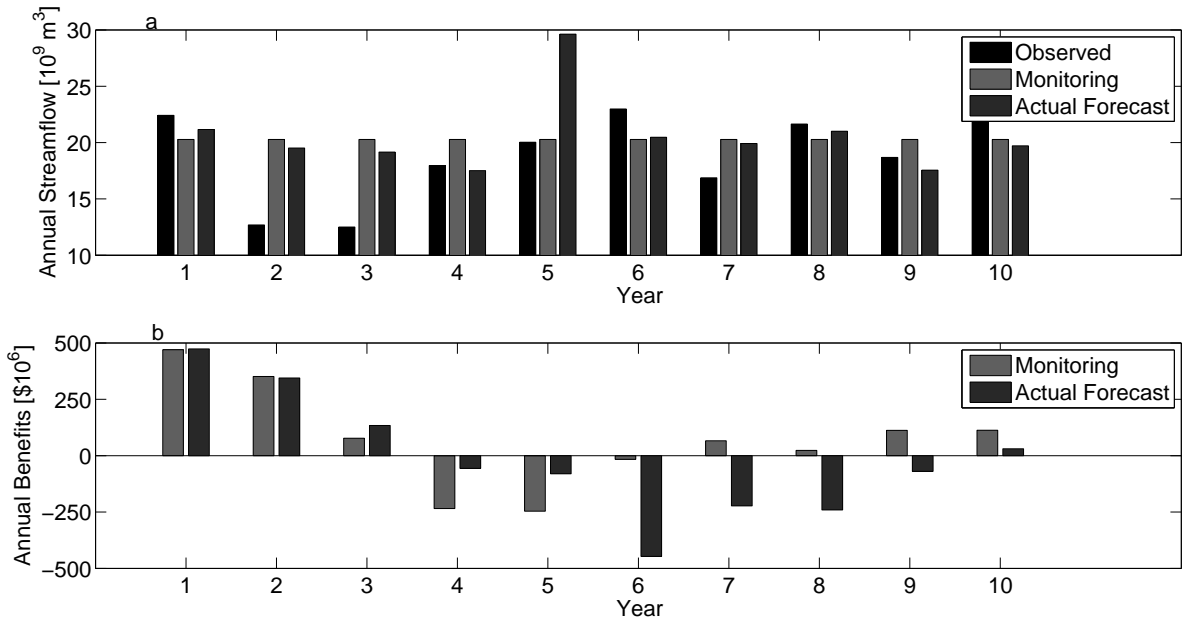

Fig. 7. Annual analysis of decadal time-series $A$ as identified in Fig. 6. (a) Annual streamflow based on observed, monitoring (climatology), and actual forecast precipitation. (b) Annual discounted hydropower benefits based on monitoring and actual forecast linked model approaches.
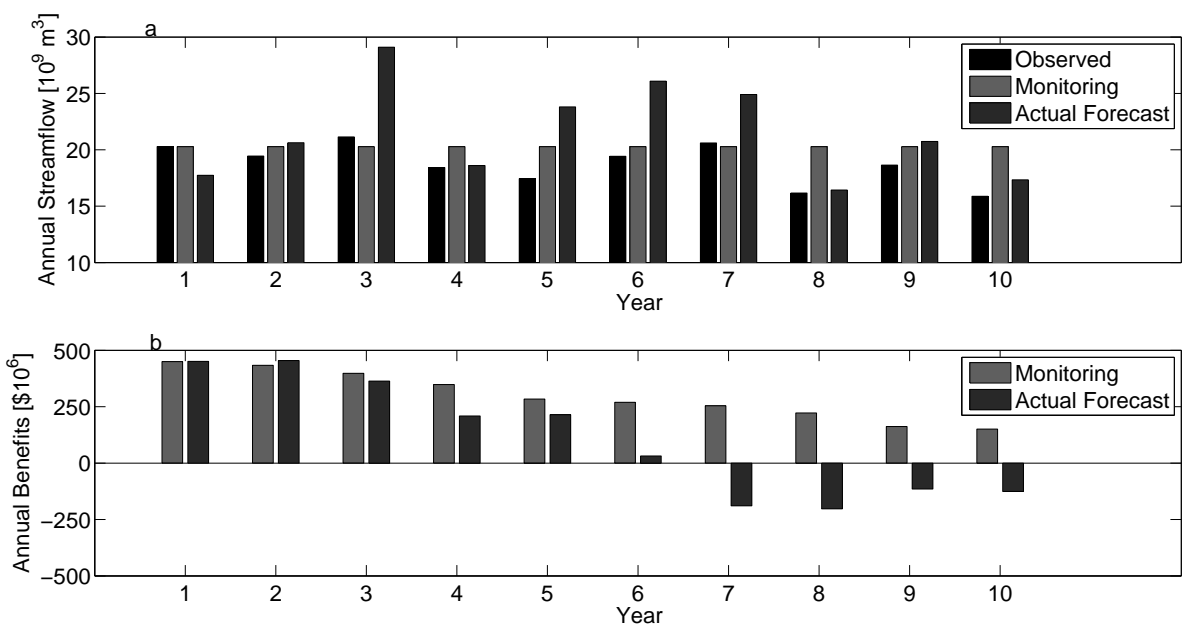

Fig. 8. Same as Fig. 7, except using time-series $B$ from Fig. 6.

findings explain the poor performance of the actual forecast for decades $A$ and $B$ under the multi-reservoir scheme (not shown).

\subsection{Tailoring the seasonal forecast}

Undeniably, water managers considering implementation of a seasonal forecast into operations would prefer the vast majority (or all!) of the project benefits reside above the 1-to-1 line. While the results of the actual forecast system demonstrated thus far indicate potentially greater benefit value versus a monitoring approach, tailoring the forecast in response to hydropower model sensitivities is worth exploring.

Examining the actual forecast errors (1961-2000) by terciles (i.e. below normal, near normal, above normal) reveals approximately equal error means and standard deviations across each category, implying no inherent bias in the forecast. Hydropower response to forecast errors across terciles, however, is less even; the model appears to express much greater sensitivity to forecast errors in the above normal category versus the below normal one. To test, a synthetic sequence is created for the above (below) normal category: June-September precipitation for each year is set at the 75th percentile (25th percentile) of the observational record to represent consistently above (below) normal conditions; remaining months are set to climatology. To mimic a forecast error, two additional sequences are created by adding (subtracting) $25 \mathrm{~mm}$ of monthly precipitation from each of the June-September months to the above (below) normal synthetic sequence. The choice of $25 \mathrm{~mm}$ is arbitrary. Both sequences are passed through the linked model system (no forecast). The synthetic sequences act as "observations" 
Table 3. Results of hydropower sensitivity test to forecast errors in above and below normal terciles. Single-reservoir scheme only based on bootstrapped sequences.

\begin{tabular}{lccl}
\hline Series & \multicolumn{2}{c}{ Aggregated Benefits (million \$) } & Difference \\
\cline { 2 - 3 } (single reservoir scheme) & Observed & Observed with Error & \\
\hline AN series (75th percentile) & 3682 & 2272 & $1410,38.3 \%$ \\
BN series (25th percentile) & 2975 & 2745 & $230,7.8 \%$ \\
\hline
\end{tabular}

Notes: $\mathrm{AN}=$ above normal precipitation, $\mathrm{BN}=$ below normal precipitation; percentile based on observational 1961-2000 record; error is $+25 \mathrm{~mm} / \mathrm{mo}$ for June-September for AN, $-25 \mathrm{~mm} / \mathrm{mo}$ for BN

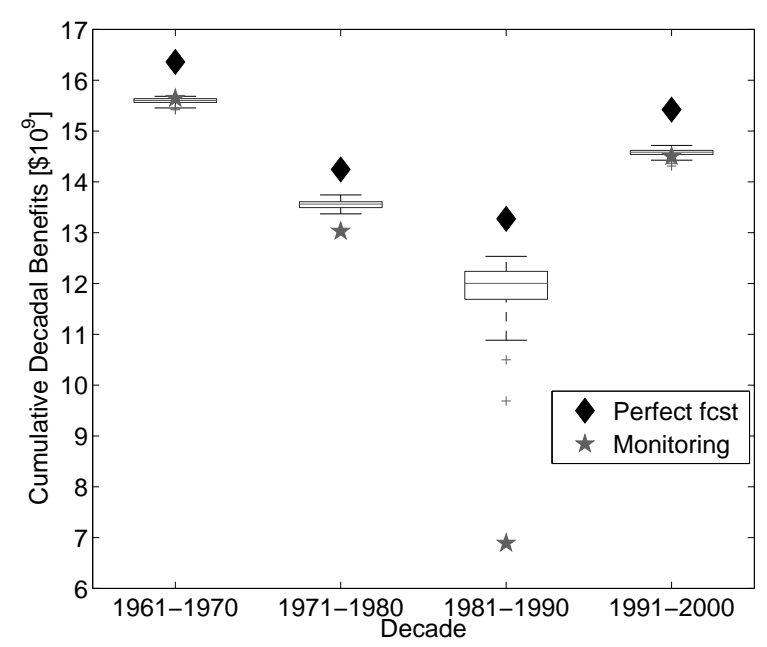

Fig. 9. Cumulative decadal hydropower benefits for four observed decades using the perfect (diamond), monitoring (climatology, star), and actual (box plots) precipitation forecasts for the four-reservoir scheme. Box plots characterize the expected benefit distribution of the 100 sequences drawn from the forecast distributions tailored to dampen above and near normal precipitation forecasts.

(constant over the decade for simplicity) for comparison with sequences containing forecast errors through a systematic bias; this allows for gauging the effects of forecast errors in the two terciles in a fair manner. Comparison of differences between "observed" and "observed with forecast error" sequences (Table 3 ) clearly exhibits greater hydropower model sensitivity to above normal forecast errors. Thus, for this linked model system, errantly forecasting wetter than observed conditions in the above normal category appears to be more detrimental to hydropower operations and ensuing benefits than errantly forecasting drier than observed conditions in the below normal category. This typically stems from aggressive actions (e.g. significant release from storage) following a wet forecast as opposed to conservative actions (e.g. maintaining storage) following a dry forecast. Therefore dampening "wet" forecasts and retaining "dry" forecasts is a reasonable option in light of this sensitivity.

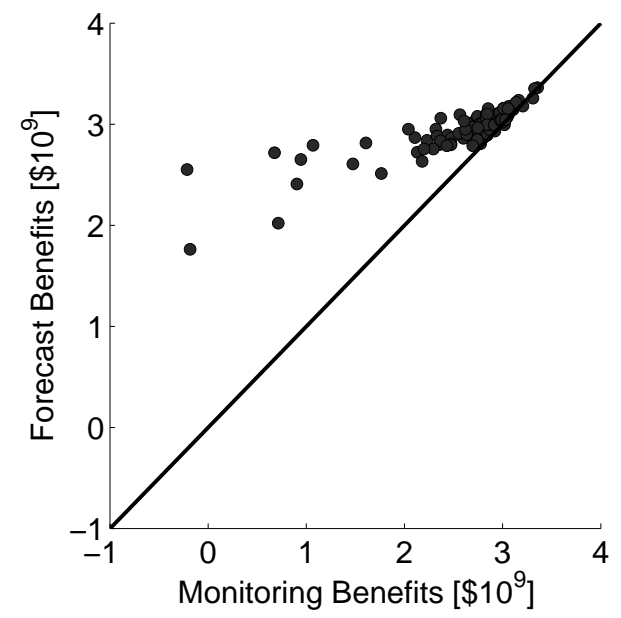

Fig. 10. Comparison of hydropower benefits between monitoring and actual tailored forecast linked model approaches for the singlereservoir (Karadobi) scheme using the bootstrapped sequences. Tailored approach includes dampening of above and near normal precipitation forecasts.

To this end, the precipitation forecast is tailored such that all actual forecasts in the above normal and near normal terciles are modulated to reflect climatology. (Little is gained from a near normal forecast in comparison to climatology.) Practically, this implies replacing occurrences of June-September forecasts of near or above normal conditions with June-September average monthly precipitation. This procedure effectively eliminates wet forecasts; some opportunities are clearly lost, however damages due to poor wet forecasts deem them worthy of disregarding. Actual forecasts in the below normal category remain unchanged. This modification has no effect on the perfect or monitoring forecast system approaches. The effect of this tailored forecast in comparison to the monitoring approach is quite dramatic (Figs. 9 and 10, updating Figs. 5 and 6a, respectively). Decadal and annual reliability and resilience scores, presented in Tables 1 and 2, indicate a marked improvement over the actual full forecast approach. For the first three observed decades (Fig. 9), the benefit distributions are notably higher and tighter; box plot medians surpass the monitoring benefits for all decades except the 1960s. Even though reliability for the 1960s is still relatively low, the difference between benefits from the actual and monitoring approaches has been reduced substantially. Decadal sequence benefits from the bootstrapped actual tailored forecast approach nearly always outpace those of the monitoring approach, with the few favoring the monitoring approach in close proximity to the 1to-1 line. The elimination of low or negative decadal benefits from the actual forecast system is promising, and may begin to entice managers to incorporate such methodologies into their practices. The relatively low annual reliability reported for the bootstrapped sequences, may be deceiving, and is best 


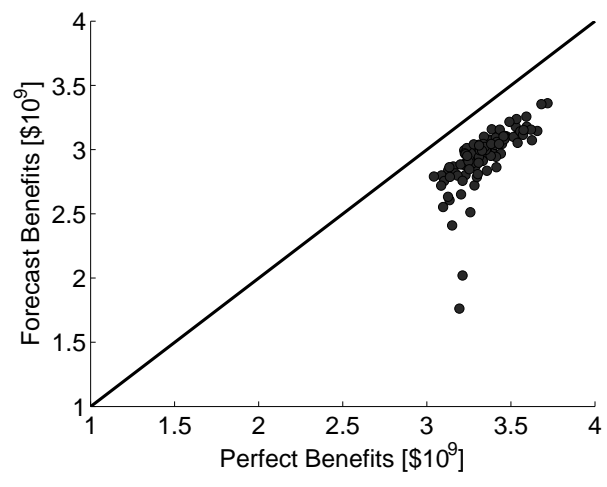

Fig. 11. Comparison of hydropower benefits between perfect and actual tailored forecast model approaches for the single-reservoir (Karadobi) scheme using the bootstrapped sequences.

understood in context. To take an example, in a dry year, benefits from the monitoring approach may outpace the actual forecast approach, as it prescribes the release of more water through the turbines that year, however repercussions to benefits in the following year are likely to be more severe for the monitoring case. The resilience metric addresses this issue, indicating a rebound by the actual forecast approach in the following year for more than two-thirds of the occurrences.

While tailoring the actual forecast to this stage is clearly beneficial, incentives to improve the forecast model to potentially draw even greater returns is evident through comparison with the perfect forecast output (Fig. 11, bootstrapped sequences only). Attaining a perfect forecast may be unrealistic due to inherent climate uncertainty, however the potential for further advancement plainly exists.

\subsection{Assessing behavioral risk outcomes}

The level of risk a water manager is willing to accept is intrinsically tied to institutional requirements, user demands, the flexibility of the system, and personal experiences, among other influences. This level implies consequent effects on system reliability and benefits. Two tendencies are addressed here through the use of a penalty function: one toward risktaking (RT), one toward risk-aversion (RA). The simple linear functions adopted to impose a penalty (represented by energy loss but effectively financial loss) in the event of a predetermined energy threshold not being exceeded is illustrated in Fig. 12. To simulate RA (RT) behavior, a steep (moderate) sloped penalty function is employed. Lowering monthly energy production below the threshold results in larger penalties.

Assessment of the two risk levels for both the monitoring and forecast approaches is undertaken for four minimum energy thresholds, selected to span conceivably acceptable levels of reliability. The identical 100 bootstrapped decadal sequences from the prior evaluation are utilized to illustrate the monthly threshold - reliability and decadal threshold -

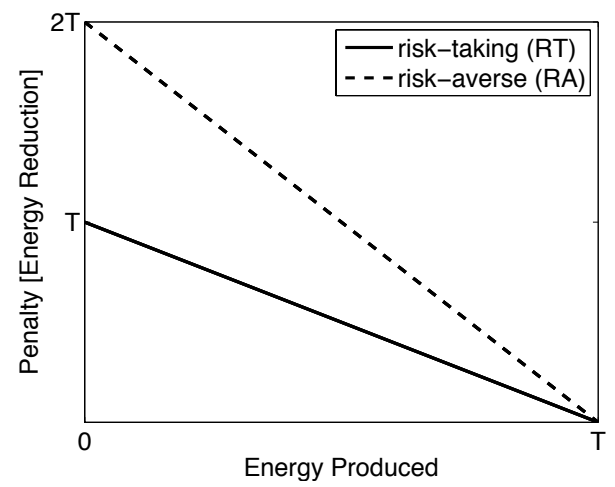

Fig. 12. Penalty functions for risk-taking (RT) and risk-averse (RA) behaviors. $T=$ energy threshold. Units for Energy Produced and Penalty are GWatth/mo.

benefits relationships (Fig. 13). Reliability here in the traditional sense refers to the number of months the threshold is exceeded for the 12000 months evaluated. Reliability and benefits substantially work in contrast to one another: higher (lower) reliability implies a reduction (increase) in benefits. Also, as the threshold level drops, the difference between levels of risk diminishes, becoming less of a factor when thresholds are easily surpassed. Of notable interest is the clear separation not simply between the monitoring and forecast approaches, but specifically between the RT monitoring and RA forecast. The RA forecast appears more stable, providing greater benefits and higher reliability over the course of thresholds evaluated. Even this conservative behavior produces superior performance when climate information is exploited, perhaps enticing mangers to consider forecast inclusion for improvements in reliability and benefits.

\section{Discussion and conclusions}

The modeling system is necessarily multi-disciplinary, linking climate, hydrology, and water management, an approach to valuing climate information that is often neglected due to its challenges and time consuming nature (Mjelde, 1999). The independent models themselves do not constitute new methodology; the uniqueness of the contribution comes in model integration, the exploitation of sensitivities between integrated models, and ultimately a clear demonstration of economic value through actual forecast inclusion. Ritchie et al. (2004) assert that a forecast system may be considered useful if the forecast is statistically valid (verified) and demonstrates a positive value of information, both of which appear true for this study.

The realization of added value and reliability through forecast inclusion, specifically addressed by dynamic management and decision-making through tailored climate information, is an important outcome. The retention of dry state forecasts adds quality information without subjecting the 


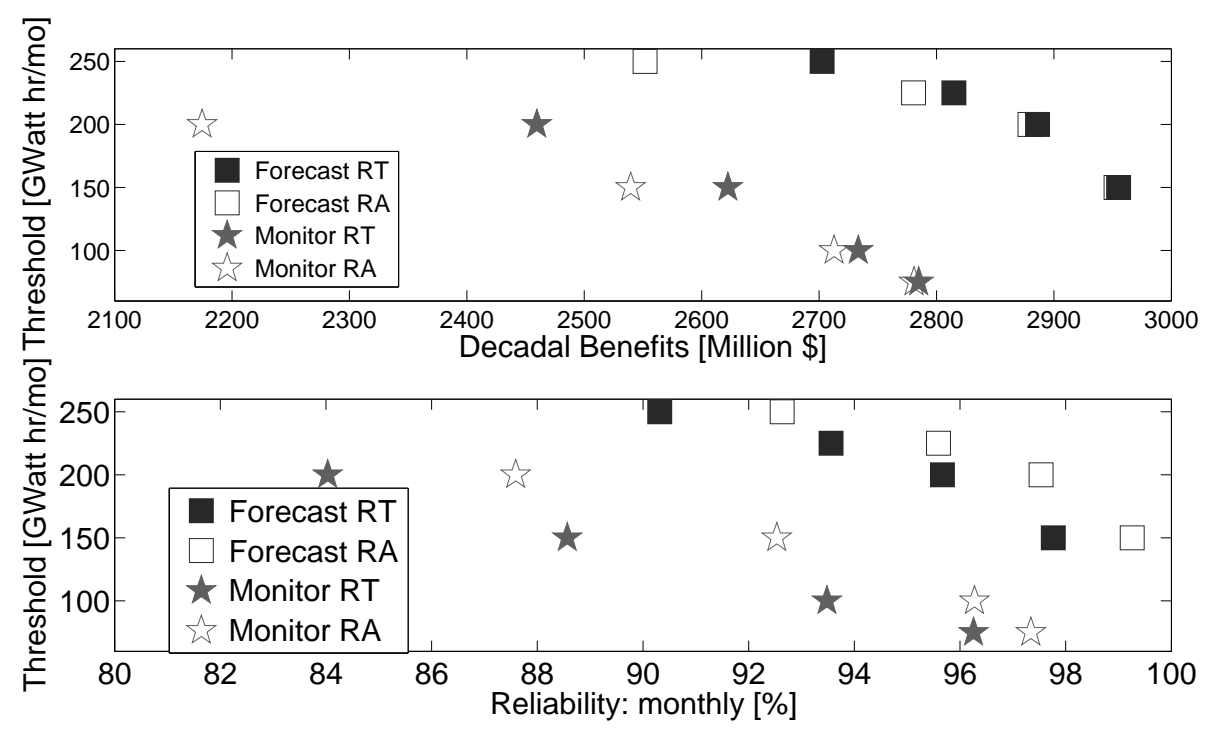

Fig. 13. Comparison of monitoring and forecast approaches under risk-taking (RT) and risk-averse (RA) behavior for (a) threshold - benefit and (b) threshold - reliability relationships using the bootstrapped sequences.

hydropower model to unreasonable levels of operational risk. Dry forecasts typically prescribe conservative reservoir action, and even if in error, will only forfeit minimal benefits (a higher than expected rainfall will still deliver streamflow to the reservoir for use in later months). Although only exploiting a subset of the forecast range, and likely sacrificing benefits in wet years, a water manager may be inclined to adopt a mechanism that focuses more on reducing risk and potentially lost benefits than lost opportunities. This begins to address one historical impediment to forecast inclusion of not focusing sufficiently on user needs and applications (Ziervogel et al., 2010).

Equally informative is the recognition of forecast benefit from a risk perspective. Risk-averse managers typically face constraints coercing conservative action, whereas risk-takers have more latitude to absorb a low-output time-step in exchange for a substantial payoff later, typically leading toward greater aggregate benefits. Given the success of forecast inclusion demonstrated, it is rather expected that for a specified level of risk, utilizing a forecast produces benefits and reliability in excess of simply depending on climatology. More enlightening is how even conservative action bolstered by a forecast regularly outperforms a risk-taking approach conditioned on climatology, for equivalent energy threshold requirements. This addresses one of the cardinal impediments (risk-aversion) by theoretically allowing managers to remain risk-averse and realize considerable gains.

While the tailored approach demonstrated in this study is effective, it is errant to assume an identical procedure conducted for other regions or project types will necessitate improved benefits, however given success here, exploration is warranted. Locations susceptible to climate variability where forecast skill is apparent are ripe for investigation. As in this instance, it is also conceivable that decisions in other sectors (agriculture and food security, flood early warning, health, etc.) may likewise tend toward emphasis on one end of the forecast spectrum, although minimal evidence of demonstration currently exists.

In addition to climate, sensitivity to coincident drivers (policy, economics, demand, etc.) may also exhibit significant influence, warranting a reassessment of the hydropower model. Explicitly modeling operational practices, such as selection of a target precipitation or streamflow forecast based on exceedance probabilities (e.g. 90th percentile) of the ensemble forecast, also deserves attention. Other integrated and social factors may also be equally relevant and worthy of inclusion, beyond hydropower simulation, as advocated by the World Commission on Dams (WCD, 2000). The interrelationship of all these aspects is not trivial or currently well understood, however, potentially complicating decisionmaking (McCartney, 2007).

Minimal difference in streamflow was noted when substituting climatological temperature for observed temperature in the rainfall-runoff model. Although the absolute hydropower benefits may be slightly overestimated, from a comparison perspective between forecast and non-forecast approaches, it is essentially immaterial, as both approaches benefit nearly equivalently. Adding a temperature forecast, conditioned on the precipitation forecast, is an added layer of complexity for future stages of this research.

The forecast model presented here is generally founded on stationary climate principles. Multi-decadal effects or climate change are not explicitly addressed. A recent study by O'Connor et al. (2005) reveals the strongest determinant of forecast use is risk perception; if extreme climate conditions are anticipated in the near future, the uptake of a forecast is 
more likely. Climate change may pose such a perception. Integrating an adaptive forecast model into the linked system to explore implications of changing precipitation trends and variability and increasing temperature warrants future attention.

Acknowledgements. This paper is funded by a grant/cooperative agreement from the National Oceanic and Atmospheric Administration, NA0OAR4311004. The views expressed herein are those of the authors and do not necessarily reflect the views of NOAA or any of its subagencies. Special thanks are given to Alessandra Giannini and Michael Tippet of IRI for their guidance and advice.

Edited by: S. Uhlenbrook

\section{References}

Axel, J., and Céron, J. P.: Elements for Life, J. Griffiths, Ed., Tudor Rose, London, 70-71, 2007.

Barnston, A. G., van den Dool, H. M., Rodenhuis, D. R., Ropelewski, C. R., Kousky, V. E., O’Lenic, E. A., Livezey, R. E., Zebiak, S. E., Cane, M. A., Barnett, T. P., Graham, N. E., Ji, M., and Leetmaa, A.: Long-Lead Seasonal Forecasts - Where Do We Stand?, B. Am. Meteorol. Soc., 75, 2097-2114, 1994.

Barnston, A. G., Kumar, A., Goddard, L., and Hoerling, M. P.: Improving seasonal prediction practices through attribution of climate variability, B. Am. Meteorol. Soc., 86(1), 59-72, 2005.

Block, P. and Strzepek, K.: Economic Analysis of Large-scale Upstream River Basin Development on the Blue Nile in Ethiopia Considering Transient Conditions, Climate Variability, and Climate Change, J. Water Res. Pl.-ASCE, 136(2), 156-166, 2010.

Block, P. and Rajagopalan, B.: Interannual Variability and Ensemble Forecast of Upper Blue Nile Basin Kiremt Season Precipitation, J. Hydrometeorol., 8(3), 327-343, 2007.

Block, P., Strzepek, K., Rosegrant, M., and Diao, X.: Impacts of Considering Climate Variability on Investment Decisions in Ethiopia, J. Agr. Econ., 39, 171-181, 2008.

Bodo, B.: Monthly Discharge Data for World Rivers, http://dss. ucar.edu/datasets/ds552.1 (last access: June 2005), 2001.

Broad, K., Pfaff, A., Taddei, R., Sankarasubramanian, A., Lall, U., and Souza Filho, F. A.: Climate, stream flow prediction and water management in northeast Brazil: societal trends and forecast value, Climatic Change, 84(2), 217-239, 2007.

Bureau of Reclamation: US Department of Interior, Land and Water Resources of Blue Nile Basin, Ethiopia, Main Report and Appendices I-V, Government Printing Office, Washington, DC, 1964.

Chiew, F. H. S., Zhou, S. L., and McMahon, T. A.: Use of seasonal streamflow forecasts in water resources management, J. Hydrol., 270(1-2), 135-144, 2003.

Central Intelligence Agency - CIA: The World Factbook, CIA, Washington, DC, 2006.

Craven, P. and Wahba, G.: Smoothing noisy data with spline functions, J. Numer. Math., 31, 377-403, 1979.

Dai, A., Trenberth, K., and Qian, T.: A global data set of Palmer Drought Severity Index for 1870-2002: Relationship with soil moisture and effects of surface warming, J. Hydrometeorol., 5, 1117-1130, 2004.
Datta, B. and Burges, S. J.: Short-term, single, multiple purpose reservoir operation: Importance of loss function and forecast errors, Water Resour. Res., 20(9), 1167-1176, 1984.

Datta, B. and Houck, M. H.: A stochastic optimization model for real-time operation of reservoirs using uncertain forecasts, Water Resour. Res., 20(8), 1039-1046, 1984.

Draper, A.: Implicit Stochastic Optimization with Limited Foresight for Reservoir Systems, Ph.D. Dissertation, University of California - Davis, 2001.

Faber, B. A. and Stedinger, J. R.: Reservoir optimization using sampling SDP with ensemble streamflow prediction (ESP) forecasts, J. Hydrol., 249(1-4), 113-133, 2001.

FAO - Food and Agriculture Oranization of the UN Crop Evapotranspiration: Guidelines for Computing Crop Water Requirements, FAO Irrigation and Drainage Paper No. 56, Food and Agriculture Organization of the United Nations, Rome, 300 pp., 1998.

Hamlet, A. F., Huppert, D., and Lettenmaier, D. P.: Economic value of long-lead streamflow forecasts for Columbia River hydropower, J. Water Res. Pl.-ASCE, 128(2), 91-101, 2002.

Hellmuth, M. E., Moorhead, A., Thomson, M. C., and Williams, J.: Climate Risk Management in Africa: Learning from Practice, International Research Institute for Climate and Society (IRI), Columbia University, New York, 104 pp., 2007.

Helsel, D. and Hirsch, R., Statistical methods in water resources, Elsevier Science, Amsterdam, 1995.

Goddard, L., Barnston, A. G., and Mason, S. J.: Evaluation of the IRI's "net assessment" seasonal climate forecasts: 1997-2001, B. Am. Meteorol. Soc., 84, 1761-1781, doi:10.1175/BAMS-8412-1761, 2003.

Grantz, K., Rajagopalan, B., Clark, M., and Zagona, E.: Seasonal Shifts in the North American Monsoon, J. Climate, 20(9), 19231935, 2005.

Jabbar, M., Pender, J., and Ehui, S.: Policies for sustainable land management in the highlands of Ethiopia: Summary of papers and proceedings of a seminar held at ILRI, Addis Ababa, Ethiopia, 22-23 May 2000, Socio-economics and Policy Research Working Paper 30, ILRI - International Livestock Research Institute, Nairobi, Kenya, 2000.

Johnston, P. A., Ziervogel, G., and Matthew, M.: The uptake and usefulness of weather and climate information among water resource managers, Papers Appl. Geog. Conf. 30, 380-389, 2007.

Kalnay, E., Kanamitsu, M., Kistler, R., Collins, W., Deaven, D., Gandin, L., Iredell, M., Saha, S., White, G., Woollen, J., Zhu, Y., Chelliah, M., Ebisuzaki, W., Higgins, W., Janowiak, J., Mo, K. C., Ropelewski, C., Wang, J., Leetmaa, A., Reynolds, R., Jenne, R., and Joseph, D.: The NCEP/NCAR reanalysis 40-year project, B. Am. Meteorol. Soc., 77, 437-471, 1996.

Karamouz, M. and Vasiliadis, H.: Bayesian stochastic optimization of reservoir operation using uncertain forecasts, Water Resour. Res., 28(5), 1221-1232, 1992.

Kim, Y.-O. and Palmer, R.: Value of seasonal flow forecasts in Bayesian stochastic programming, J. Water Res. Pl.-ASCE, 123(6), 327-335, 1997.

Lemos, M. C.: What Influences Innovation Adoption by Water Managers? Climate Information Use in Brazil and the United States, J. Am. Water Resour. Assoc., 44(6), 1388-1396, 2008.

Loader, C.: Local Regression Likelihood, Springer, New York, 1999. 
Loucks, D. P., Stedinger, J. R., and Haith, D. A.: Water resources systems planning and analysis, Prentice-Hall, Englewood Cliffs, NJ, 1981.

Marino, M. A. and Loaiciga, H. A.: Dynamic model for multireservoir operation, Water Resour. Res., 21(5), 619-630, 1985a.

Marino, M. A. and Loaiciga, H. A.: Quadratic model for reservoir management: Application to the Central Valley Project, Water Resour. Res., 21(5), 631-641, 1985b.

Maurer, E. P. and Lettenmaier, D. P.: Potential Effects of Long-Lead Hydrologic Predictability on Missouri River Main-Stem Reservoirs, J. Climate, 17, 174-186, 2004.

McCartney, M. P.: Decision support systems for large dam planning and operations in Africa, IWMI Working Paper 119, International Water Management Institute, Colombo, Sri Lanka, 47 pp., 2007.

Millner, A.: What Is the True Value of Forecasts?, Weather Clim. Soc., 1, 22-37, 2009.

Mitchell, T. and Jones, P.: An improved method of constructing a database of monthly climate observations and associated highresolution grids, Int. J. Climatol., 25, 693-712, 2005.

Mjelde, J.: Value of Improved Information in Agriculture: Weather and Climate Forecasts, Paper for the Southern Region Information Exchange Group-10 annual meeting, Huntsville, AL, 2021 May, 32 pp., 1999.

MoFED - Ministry of Finance and Economic Development Ethiopia: Status Report on the Brussels Programme of Action for Least Developed Countries, Addis Ababa, Ethiopia, www.un.org/special-rep/ohrlls/ldc/MTR/Ethiopia.pdf (last access: March 2010), 2006.

O’Connor, R. E., Yarna, B., Dow, K., Jocoy, C., and Carbone, G.: Feeling at Risk Matters: Water Managers and the Decision to Use Forecasts, Risk Anal., 25(5), 1265-1275, 2005.

Pagano, T., Hartmann, H., and Sorooshian, S.: Using climate forecasts for water management: Arizona and the 1997-1998 El Niño, J. Am. Water Resour. Assoc., 37(5), 1139-1153, 2001.

Patt, A. G., Ogallo, L., and Hellmuth, M.: Learning from ten years of climate outlook forums in Africa, Science, 318, 49-50, 2007.

Pulwarty, R. and Redmond, K.: Climate and Salmon Restoration in the Columbia River Basin: The Role and Usability of Seasonal Forecasts, B. Am. Meteorol. Soc., 78(3), 381-397, 1997.

Rayner, S., Lach, D., and Ingram, H.: Weather forecasts are for wimps: Why water resource managers do not use climate forecasts, Climatic Change, 69(2-3), 197-227, 2005.

Ritchie, J. W., Zammit, C., and Beal, D.: Can seasonal climate forecasting assist in catchment water management decision-making?: A case study of the Border Rivers catchment in Australia, Agr. Ecosyst. Environ., 104(3), 553-565, 2004.
Sankarasubramanian, A., Lall, U., Souza Filho, F. A., and Sharma, A.: Improved water allocation utilizing probabilistic climate forecasts: Short-term water contracts in a risk management framework, Water Resour. Res., 45, W11409, doi:10.1029/2009WR007821, 2009.

Shahin, M.: Hydrology of the Nile Basin, Elsevier Science, Amsterdam, The Netherlands, 1985.

Singhrattna, N., Rajagopalan, B., Clark, M., and Krishna Kumar, K.: Forecasting Thailand summer monsoon rainfall, Int. J. Climatol., 25, 649-664, 2005.

Stedinger, J. R., Sule, B. F., and Loucks, D. P.: Stochastic dynamic programming models for reservoir optimization, Water Resour. Res., 20(11), 1499-1505, 1984.

Steenhuis, T. S., Collick, A. S., Easton, Z. M., Leggesse, E. S., Bayabil, H. K., White, E. D., Awulachew, S. B., Adgo, E., and Ahmed, A. A.: Predicting discharge and sediment for the Abay (Blue Nile) with a simple model, Hydrol. Process., 23, 37283737, 2009.

Sutcliffe, J. and Parks, Y.: The hydrology of the Nile, IAHS Press, Wallingford, Oxfordshire, UK, 1999.

Tegenu, A.: Statement at the Fourteenth Commission on Sustainable Development, United Nations, New York, www.un.org/esa/ sustdev/csd/csd14/statements/ethiopia_11may.pdf (last access: March 2010), 2006.

Thomson Gale Encyclopedia of the Nations - Africa: Thomson Corporation, Farmington Hills, MI, USA, 2006.

WCD - World Commission on Dams, Dams and Development: A New Framework for Decision-making, Earthscan Publications Ltd., London, 404 pp., 2000.

World Energy Council, 2007: Survey of Energy Resources, World Energy Council, London, 586 pp., 2007.

Yao, H. and Georgakakos, A.: Assessment of Folsom Lake response to historical and potential future climate scenarios: 2. Reservoir management, J. Hydrol., 249(1-4), 176-196, 2001.

Yates, D.: WatBal: An Integrated Water Balance Model for Climate Impact Assessment of River Basin Runoff, Int. J. Water Resour. D., 12(2), 121-139, 1996.

Yates, D. and Strzepek, K.: Modeling the Nile basin under climate change, J. Hydrol. Eng., 3, 98-108, 1998.

Yeh, W. W.-G., Becker, L., and Zettlemoyer, R.: Worth of inflow forecast for reservoir operation, J. Water Res. Pl.-ASCE, 108(3), 257-269, 1982.

Ziervogel, G., Johnston, P., Matthew, M., and Mukheibir, P.: Using climate information for supporting climate change adaptation in water resource management in South Africa, Climatic Change, 103(3-4), 537-544, 2010. 